\title{
¿Quién impugna qué marcos? Tensiones en torno de la exhibición de la muestra fotográfica Prisioneros de la Ciencia
}

Who contests which frames? Tensions around the photographic exhibition Prisoners of Science

\section{Tozzini María Alma}

\section{(2) OpenEdition \\ Journals}

\section{Edición electrónica}

URL: http://journals.openedition.org/corpusarchivos/2882

DOI: 10.4000/corpusarchivos.2882

ISSN: 1853-8037

Editor

Diego Escolar

\section{Referencia electrónica}

Tozzini María Alma, « ¿Quién impugna qué marcos? Tensiones en torno de la exhibición de la muestra fotográfica Prisioneros de la Ciencia », Corpus [En línea], Vol. 9, No 1 | 2019, Publicado el 02 julio 2019, consultado el 04 julio 2019. URL : http://journals.openedition.org/corpusarchivos/2882 ; DOI : 10.4000/corpusarchivos.2882

Este documento fue generado automáticamente el 4 julio 2019. 


\title{
¿Quién impugna qué marcos?
} Tensiones en torno de la exhibición de la muestra fotográfica Prisioneros de la Ciencia

\author{
Who contests which frames? Tensions around the photographic exhibition \\ Prisoners of Science
}

Tozzini María Alma

\section{NOTA DEL EDITOR}

Fecha de recepción del original: 10/09/2018

Fecha de aceptación para publicación: 28/11/2018

\section{Viñeta 1}

1 Año 2013. Visita guiada al "Espacio Memoria y Derechos Humanos"; ${ }^{1}$ al ir recorriendo las dependencias donde se encontraban alojados los detenidos-desaparecidos, y ante la pregunta de una de las visitantes en relación con la falta de objetos y de imágenes, el guía explica que la austeridad del espacio respondía, en primer lugar, a que no se lo podía intervenir en virtud de causas judiciales abiertas y de las cuales el espacio era prueba material y, en segundo lugar, a que había un acuerdo en no "reproducir el horror".

\section{Viñeta 2}

2 Año 2017. En un seminario de doctorado sobre la obra de Judith Butler, y trabajando en torno al texto "Cuerpos que importan", la docente nos relató un incidente ocurrido unos 
años antes en un seminario sobre memoria reciente, en España. En uno de los encuentros, una socióloga argentina presentó un trabajo sobre la materialidad de los cadáveres de los desaparecidos; ilustró su intervención con unas fotografías de cuerpos de desaparecidos que habían emergido en la costa del Uruguay y que ya habían sido publicadas por la prensa gráfica. ${ }^{2}$ En el seminario se encontraba una hija de desaparecidos quien calificó de "obscena" la intervención de su compañera, cuestionando éticamente su trabajo. Cuando esta última presentó su trabajo, que versaba sobre la genealogía histórica de la apropiación, exhibió una foto de la joven Damiana ${ }^{3}$ desnuda, aunque con sus senos censurados. Inmediatamente, varios de los presentes interpelaron a su autora, preguntándole si no era, en todo caso, igual de obsceno exhibir ese cuerpo desnudo violentado. La autora repudió tal comparación.

\section{Introducción}

Como cada año, en el marco del Día Nacional de la Memoria por la Verdad y la Justicia en conmemoración del 24 de marzo de 1976 en que dio inicio la última dictadura cívicomilitar en la Argentina-, el Instituto de Formación Docente Continua de El Bolsón ${ }^{4}$-en la provincia de Río Negro, Patagonia argentina- destinó una semana a distintas actividades relacionadas con la efeméride. Como cada año, también, sus bibliotecarios producirían una muestra gráfica, o bien gestionarían el envío de alguna muestra fotográfica para exhibir en el pasillo central de la institución.

4 En los últimos tres años, la efeméride del 24 de marzo había estado acompañada por distintas muestras fotográficas de la Asociación de Reporteros Gráficos de la República Argentina (ARGRA). ${ }^{5}$ Este año, sin embargo, al ponerse en contacto los bibliotecarios con dicha entidad, se les sugirió solicitar la muestra del Colectivo GUIAS, ${ }^{6}$ "Prisioneros de la Ciencia", q que también había sido exhibida en el Espacio de Memoria y Derechos Humanos donde ARGRA tenía su locación. Así fue que, orientados por el tópico del "Terrorismo de Estado", los bibliotecarios evaluaron que se trataba de una muestra que se ajustaba perfectamente para trabajar la efeméride "desde otro lado", diferente al que venían habituados a hacerlo.

5 La muestra llegó al Instituto el 15 de marzo y, apenas abierto el embalaje que la contenía, las certezas que en un principio guiaron la gestión de su envío y la pertinencia de traerla, se escurrieron entre las manos. Tal como manifestó uno de los bibliotecarios en el acto de apertura, y posteriormente en una entrevista, si bien se conocía cuál era el objetivo de la muestra -la denuncia- así como el contexto en el cual las fotografías habían sido tomadas -el cautiverio de indígenas luego de la avanzada militar argentina sobre sus territorios a fines del siglo XIX- las imágenes de personas desnudas que, por estar en cautiverio estaban obligadas a posar de esa forma, despertaron aflicción e inquietud respecto de la pertinencia de exhibirlas.

6 Esta no era la primera vez que una muestra fotográfica generaba dudas a alguno de los miembros de la institución y se ponía en discusión la pertinencia de su exhibición. En efecto, el año anterior la muestra "Archivos Incompletos" de ARGRA había sido cuestionada. Compuesta por fotografías tomadas por las fuerzas represivas a mediados de la década de 1970 y publicadas en medios gráficos en pos de construir la idea de "enemigo interno", un docente, haciéndose eco de algunos miembros de organizaciones sociales, había solicitado su remoción ante el temor que la muestra reprodujera dichos repertorios 
justificatorios de la represión. El pedido se había realizado en pleno auge del discurso de la Alianza Cambiemos que - mientras funcionarios del gobierno se reunían con familiares de genocidas (Barros y Morales, 2016) - quitaba de foco -y de agenda- la última dictadura cívico-militar como problema central de los derechos humanos en nuestro país. Así, a la vez que el presidente electo se había referido a las anteriores políticas sobre el tópico como "el curro de los derechos humanos" con el que venía a terminar, otros funcionarios - como el Ministro de Cultura de la Ciudad Autónoma de Buenos Airescuestionaban la cifra de desaparecidos; 8 al ritmo que se desmantelaban varios programas estatales que tenían la reivindicación de los ejes de memoria, verdad y justicia como prioritarios (Barros y Morales, 2016). De todos modos, en aquella ocasión se decidió institucionalmente no retirar la muestra de ARGRA, pues mostrar tal entramado ayudaba a crear la conciencia necesaria para no repetirlo. ${ }^{9}$ Sin embargo, en 2018, las dudas que generaba la muestra de GUIAS ponían en entredicho las certezas que habían guiado la decisión el año previo.

7 La tensión se incrementó al interior de la institución y se citó -para que se pronunciara al respecto-a la comunidad mapuche Las Huaytecas que, si bien no era la única en la zona, con ella el Instituto articulaba desde hacía más de una década, razón por la cual existía una relación de confianza mutua. ${ }^{10}$ Se la convocó por su trabajo en las restituciones de los restos del Lonko Inacayal en 2014 en Tecka (Chubut) y por su solicitud al Museo de Ciencias Naturales de La Plata de los de Margarita Foyel, concretada en 2015. Mientras duró el proceso de consulta a la comunidad, el Colectivo GUIAS -quien consideraba "soberana" la decisión que tomara la misma- retiró momentáneamente la muestra hasta que aquella se expidiera. Finalmente, los miembros de Las Huaytecas solicitaron no exhibir las fotos de desnudos.

Institucionalmente esto derivó en una suerte de separación entre los docentes que acordaron "recortar" la exhibición para ser respetuosos del mandato de la comunidad; y aquellos que evaluaron que una muestra que ya venía armada no podía desarmarse y que, en consecuencia, o se la montaba completa o se la devolvía. Este grupo tampoco acordaba con señalar como "problemáticas" a las fotos con desnudos, pues entendía que todas las fotos (con o sin desnudos) daban cuenta de situaciones de humillación. Otro grupo, aun comprendiendo los reparos de la comunidad, asumía -al igual que lo habían hecho frente al conflicto con la muestra de ARGRA- que el armado mismo por parte del Colectivo GUIAS tenía una función impugnadora que permitía tematizar y denunciar la humillación para no repetirla. Finalmente, un grupo de docentes recuperaba el valor estético y pedagógico de las imágenes y -en tanto las fotografías retiradas fueron aquellas de cuerpos desnudos- ligaron esta acción a cuestiones de "censura" argumentando que en el Instituto costaba que los jóvenes permanecieran en las clases de dibujo donde se trabajaba con modelos desnudos. Unido a esta cuestión, un docente de este último grupo sostenía que se habían conocido y publicado fotos de desaparecidos desnudos y que entonces por qué se ponían reparos cuando las fotos de desnudos eran de indígenas que, al igual que los desparecidos fotografiados, estaban en cautiverio.

9 Parto para el análisis de esta situación de mi trabajo de campo sobre identificaciones e interpelaciones indígenas y del análisis de las distintas posturas que se esgrimieron en el acto de apertura de la muestra fotográfica, más algunas conversaciones mantenidas a posteriori con algunos de los actores. ${ }^{11}$ Sin pretender tomar posición respecto de dichas posturas, ni llevar el análisis hacia una justificación de una u otra, me mueve poder 
analizar - desde la teoría de los marcos de Judith Butler, y asumiendo al grupo de fotografías exhibidas en tanto "actos de habla"-, al menos dos cuestiones.

En primer lugar, analizar desde la perspectiva de los performativos perlocucionarios (Butler, 2014 [1997]) qué amenaza o posibilidad de herir se consideraba inherente a las fotos y, como telón de fondo, poder comparar con el conflicto acaecido el año anterior a propósito de la muestra de ARGRA "Archivos Incompletos".

11 En segundo lugar, entender dichas impugnaciones desde la teoría de los marcos de Butler (2010 [2009]) para poder comprender qué devenía visible o -por el contrario- qué desaparecía en los distintos marcos desde los que las fotografías fueron leídas, así como qué encuentros éticos (Butler, 2009 [2005]) se propiciaban o anulaban según se miraran las fotografías desde el marco original de su producción o desde el montaje del Colectivo GUIAS.

12 Sin embargo, y antes de entrar de lleno en el trabajo sobre estos dos objetivos, resulta fundamental reponer las características de la muestra y describir el contexto institucional y regional en el cual se la pretendía exhibir, para comprender qué disputas, tal vez menos audibles, se jugaban en la impugnación que la muestra recibía.

\section{Prisioneros de la Ciencia: contextos y repertorios discursivos}

13 La muestra del Grupo GUÍAS está compuesta - según reza su página web ${ }^{12}$ - de fotografías tomadas por investigadores del Museo de Ciencias Naturales de La Plata, en Santa Cruz, Tierra del Fuego y en el mismo museo, a sobrevivientes de las expediciones militares de fines del siglo XIX. Así, las fotografías dan cuenta del destino que tuvieron los cuerpos del cacique Inacayal y su familia, quienes murieron prisioneros en el museo. También dan cuenta del caso del cacique Orkeke y de los prisioneros de los pueblos originarios de Tierra del Fuego, cuyos cuerpos se encuentran en las "colecciones" del museo platense. Al estar las personas cautivas, todas ellas son fotos donde las mismas son obligadas a posar frente a una cámara. Hay algunas fotos grupales, especialmente de mujeres y niños, otras donde los caciques Inacayal y Foyel -ancestro este último de la comunidad Las Huaytecas - posan solos y otras donde las personas son fotografiadas desnudas o semi-desnudas. Las fotografías están concebidas desde lo que los autores decoloniales han dado en llamar la matriz colonial de poder (Gómez y Mignolo, 2012); su marca queda establecida de maneras diferenciales pues se exhibe, por un lado, el poder del sometimiento (Schlenker, 2012), ya sea en las señales de agresión física o en los cabellos cortados de manera similar en los hombres; por el otro, la exotización colonial, como es el caso de las personas fotografiadas desnudas. ${ }^{13}$ La muestra no llegó entera a El Bolsón, pues una parte de la misma se encontraba en Tierra del Fuego en el mismo período.

14 No era, sin embargo, la primera vez que se exhibía en la zona, y sus fotos no eran totalmente desconocidas para los habitantes locales. En efecto, en $2010-\mathrm{y}$ organizada por el Instituto de Investigaciones en Diversidad y Procesos de Cambio del CONICET y de la Universidad Nacional de Río Negro - se había exhibido junto a otra, "Wingka Malón" del Archivo General de la Nación- en la Sala Chonek del Museo de la Patagonia en la ciudad de San Carlos de Bariloche. Aunque no había habido ningún tipo de oposición a su exhibición, la muestra había generado disconformidad en diversos sectores; ${ }^{14}$ asimismo - 
y previendo incomodidades- se había decidido sustituir las fotos de desnudos por siluetas. ${ }^{15}$

Ahora, tal como expresamos en la introducción de este escrito, tanto el lugar geográfico donde se emplaza el Instituto de Formación Docente, así como trágicos sucesos del año 2017 que involucraron a miembros de comunidades mapuche de la zona, habían confluido en la decisión institucional de traer una muestra que denunciara el terrorismo de Estado en vínculo con la población indígena, en el marco de las conmemoraciones del 24 de marzo. Sin embargo, ese mismo contexto fue el que dio una señal que hizo dudar de la pertinencia de colgar la totalidad de las fotografías que habían sido enviadas.

Ahora bien ¿a qué contexto nos referimos? Esta pregunta merece ser respondida en varios planos. Para comenzar diremos que la institución se encuentra situada en la Comarca Andina del Paralelo $42^{\circ}{ }^{16}$ una zona particularmente atravesada por conflictos entre comunidades mapuche y grandes terratenientes o emprendimientos inmobiliarios. Por la cercanía del lugar de los hechos, estamos hablando de una geografía que se vio particularmente convulsionada a partir de dos sucesos que conmovieron la opinión pública regional y nacional. Me refiero específicamente a la desaparición y muerte del joven Santiago Maldonado en ocasión de una fuerte represión llevada a cabo por la Gendarmería Nacional en la Pu Lof en Resistencia de Cushamen, en la provincia de Chubut, en agosto de 2017, y al asesinato a manos del Grupo Albatros - de la Prefectura Naval Argentina-, del joven mapuche Rafael Nahuel, quien se encontraba acompañando una reivindicación territorial de la Comunidad Lafken Winkul Mapu en cercanías del lago Mascardi en las afueras de San Carlos de Bariloche, en la provincia de Río Negro, en el mes de noviembre del mismo año. ${ }^{17}$ Por su parte, y con la excusa de buscar pistas que pudieran conducir al joven desaparecido en agosto, varias comunidades mapuche, desde la zona de Vaca Muerta en Neuquén hasta la Comunidad de Vuelta del Río en Chubut, fueron allanadas violentamente. Los miembros de la comunidad de Vuelta del Río decidieron permanecer pacíficamente en el Juzgado Federal de Esquel reclamando la renuncia del juez que los había sometido a esa situación violenta. Al volver a la comunidad, encontraron viviendas incendiadas.

17 Este contexto de recrudecimiento del escenario represivo (Muzzopappa, Tozzini y Sabatella, 2018) dirigido -entre otros sectores- al pueblo mapuche, hizo pensar a los bibliotecarios del instituto que debía abordarse el tema del terrorismo de Estado a través del problema de la relación Estado-pueblos indígenas. Sin embargo, el hecho de que el instituto se hallara enclavado en una zona de fuerte impronta indígena llevó a poner en duda la pertinencia de exhibir ciertas fotografías donde hombres y mujeres posaban desnudos. En buena medida, porque, por los apellidos de las personas fotografiadas y por el contexto en que habían sido tomadas las fotografías, se entendía que muchos pobladores locales eran descendientes de los fotografiados. La pregunta que surgía, y que fue luego reafirmada por la misma comunidad, fue ¿qué pasa cuando los fotografiados en situaciones de humillación son familiares?; ¿es aceptable entrar a una muestra y ver una fotografía de un abuelo o bisabuelo propio desnudo y degradado?; ¿o serían fotos que preferirían resguardarse de manera privada?

18 Es decir, existía, en primer lugar una cuestión de contexto en el cual las fotografías exhibidas eran, en buena medida, de personas reconocidas como cabezas de linaje locales. Así, la comunidad planteó que eran "sus cuerpos" desnudos los que se pretendía exhibir, y algunos miembros del instituto pensaron que una cosa era que esas fotos se exhibieran en 
espacios lejanos a los hechos y a los descendientes, y otra era que un descendiente entrara a la institución y viera la fotografía de un ancestro en esa situación.

Pero esto no era lo único que daba cuenta del ánimo social que por esos meses impregnaba el ámbito local y regional.

La desaparición y muerte de Santiago Maldonado despertó ciertas tensiones a nivel local, no solamente entre quienes justificaron el accionar de la Gendarmería y quienes se manifestaron abiertamente en contra, ${ }^{18}$ sino en el seno mismo de las personas que repudiaron desde el primer momento el accionar del aparato represivo. Entre ese sector, los disensos comenzaron a suscitarse al momento de plantear estrategias de lucha y repertorios de reclamo. ${ }^{19}$ Así, cuando la desaparición del joven movilizó a amplios sectores de la sociedad, incluso fuera de la Patagonia, porque "nunca más" podía permitirse una desaparición forzada de personas a manos del Estado, lo cierto es que el motivo que llevó al joven a estar en el lugar donde desapareció se fue borroneando y esfumando a medida que se recrudecían los reclamos por su aparición con vida. Y es que, aun cuando Santiago Maldonado había estado acompañando a los miembros de Pu Lof en Resistencia de Cushamen en su reclamo por la liberación de su Lonko Facundo Jones Huala y por el derecho a estar en su territorio, estas razones comenzaban a salirse de foco. Así, y tal como lo señalan Briones y Ramos (2018), el hecho de que este conflicto estuviese ligado a una desaparición, fue desplazando el tema de los mapuche a Maldonado. Las reivindicaciones y reclamos mapuche fueron volviéndose entonces menos audibles y protagónicos frente al caso de desaparición del joven. Por su parte, distintos militantes y colectivos mapuche, sin dejar de apoyar la causa por el esclarecimiento de la desaparición y muerte de Maldonado, comenzaron a poner en evidencia cómo casos de desapariciones de personas mapuche no habían tenido trascendencia y -en consecuencia - llamaban la atención sobre "vidas que valen menos". ${ }^{20}$

21 Entonces, podemos notar cómo la presencia de la muestra en el instituto estaba atravesada por una tensión más que evidente: ¿qué hacer con fotografías humillantes de ancestros de habitantes de la zona? Por otro lado, llegaban en medio de un clima local y regional en que parte del colectivo mapuche reflexionaba críticamente sobre el poco lugar que sus desaparecidos habían tenido en la escena pública, sumado a que el conflicto de la tierra mapuche y los terratenientes había quedado opacado por la desaparición de una persona no mapuche. Aun sorteando el primer problema que planteaba la exhibición de ciertas fotos, había otro que no podía sortearse y que esta muestra hacía recrudecer: el sometimiento y el genocidio indígena eran exhibidos en el marco del 24 de marzo, en la conmemoración de las víctimas del terrorismo de Estado, en cuyo repertorio -y no en el mapuche- era ubicada públicamente la desaparición de Maldonado (Briones y Ramos, 2018). Es decir, se respiraba la idea de que se habilitaba un espacio para mostrar y hablar de genocidio indígena; pero irremediablemente el tema quedaba subsumido en el marco del genocidio perpetrado por la última dictadura cívico-militar sobre población mayoritariamente no indígena. ${ }^{21}$ Hablar de terrorismo de Estado y de genocidio, era puesto en ocasión de la conmemoración del 24 de marzo- un tema de la sociedad no indígena que se disponía a "hacer un lugar" dentro de sus repertorios de reclamo y lucha a la cuestión mapuche.

Esta heterogeneidad respecto de cómo incluir o conjugar "terrorismo de Estado" con la problemática de las comunidades indígenas, quedaba evidenciado en las alocuciones de algunos de los presentes al momento de la inauguración de la muestra. En efecto, varios se refirieron a que el terrorismo de Estado al que aludía la muestra continuaba en el 
territorio. Sin embargo, no todos se referían a lo mismo cuando enunciaban a qué etapa del terrorismo de Estado se aludía y en qué hechos se evidenciaba la continuidad. “(...) nuestros antecesores que dieron la vida por el territorio, por aquellos prisioneros políticos, los primeros prisioneros políticos que tuvo el Estado argentino" (Elisa Ose, Chillkaltufe de la Comunidad Las Huaytekas, acto de inauguración, 21 de marzo de 2018). Sin embargo, mientras Elisa Ose anclaba el terrorismo de Estado a la denominada "Conquista del desierto", otros manifestaban que el terrorismo de Estado no había concluido, que "todo esto está vivo" y ponían de ejemplo “(...) lo que sucedió con Santiago Maldonado" (Gabriela Sevlever, Bibliotecaria IFDC, acto de apertura, 21 de marzo de 2018).

El conflicto intra-institucional que generó el arribo de la muestra, también tenía como contexto el conflicto que el año previo había generado la muestra de ARGRA. Si en aquella oportunidad se decidió que los pies de fotos de la muestra, más el marco narrativo que le habían dado los bibliotecarios a la hora de montarla, eran suficientes para impugnar el mensaje que esas fotografías habían construido cuarenta y dos años atrás; no lograba, al menos para una parte de los involucrados, construirse la misma conclusión respecto de estas fotografías tomadas con más de un siglo de antigüedad.

Entonces ¿qué es lo que aún las volvía "peligrosas" o hirientes? ¿Qué es lo que hacía que el tiempo transcurrido y el hecho de que la muestra montada con un guión determinado por un grupo como GUIAS - que impugnaba aquellos actos y sucesos- no bastara para conjurar la amenaza?

Con estas preguntas iniciales vamos a desarrollar los próximos dos apartados, deteniéndonos en primer lugar en la reflexión butleriana respecto del poder de herir de ciertos actos de habla.

\section{Fotografías, dolor e interpelación humillante}

En la introducción de este escrito puntualicé que, a los fines analíticos, tomaba este grupo de fotografías en tanto actos de habla, los que fueron caracterizados por John Searle (1980) por: a) realizar actos de emisión; b) realizar actos proposicionales, c) realizar actos ilocucionarios (Searle, 1980, pp. 32-33). Ahora bien, asumiendo esta pronta asimilación entre fotografía y actos de habla y aun cuando resulta un recurso heurístico que nos permite explicar el problema bajo análisis, entiendo que tal operación requiere una primera aclaración. En la introducción de su libro Lenguaje, poder e identidad Judith Butler (2014 [1997]) abre la posibilidad de dar tal tratamiento a las fotografías - es decir, tratarlas en tanto actos de habla- al discutir con Althusser el hecho de que el único poder de interpelación -y, como explicaremos enseguida, consecuente constitución del sujetolo opere la voz hablada, considerando tomar en cuenta la eficacia del lenguaje escrito o grabado/reproducido (Butler, 2014 [1997], p. 60). Sin embargo, en el capítulo 2 de Marcos de Guerra (Butler, 2010 [2009]) - "La tortura y la ética de la fotografía: pensar con Sontag"- la autora nos permite pensar esta suerte de equiparación entre actos de habla y fotografía. En dicho capítulo discute con Susan Sontag quien desconfía de la capacidad de la fotografía de generar comprensión de los hechos aberrantes (se están refiriendo específicamente a la guerra), como sí lo consiguen, según su perspectiva, las formas narrativas. Butler se opone a la posición de Sontag de negarle a la fotografía el efecto cognitivo propio de las formas narrativas $\mathrm{y}$, analiza los efectos que las fotografías de las 
torturas en la cárcel iraquí de Abu Ghraib, por parte del ejército norteamericano, suscitaron una vez publicadas y conocidas. Postula que la fotografía no opera solo en un registro afectivo sino que instituye un modo de reconocimiento. Afirma que "la fotografía 'argumenta' y, en ese sentido, su pathos es, a la vez, afectivo e interpretativo" (Butler, 2010 [2009], p. 141).

Me permito, entonces, tomar al conjunto de fotografías de la muestra en análisis en tanto actos de habla. El paso siguiente es preguntarme, tal como lo hace Butler (2014 [1997]), ¿cómo puede el lenguaje herirnos?

Es aquí donde, en primer lugar, retoma la idea de interpelación lingüística de Althusser mencionada arriba - quien la utiliza para dar cuenta de la constitución del sujeto. El autor ejemplifica este proceso a través de la escena de un policía que se dirige a una persona que pasa; al llamarlo " $\mathrm{hh}$, tu", la persona se reconoce y gira para responder a la llamada. Es esa llamada la que lo trae al lenguaje, la que lo constituye como sujeto lingüístico. "La llamada trae al sujeto a la existencia" (Butler, 2014 [1997], p. 50). El poder de herir del lenguaje tiene sus cimientos, en primer término, en este poder interpelativo y constitutivo del lenguaje.

Siguiendo esta línea argumentativa la autora recupera el planteo de los actos de habla de Austin para analizar qué establece el carácter performativo, la fuerza de un enunciado. Los actos de habla pueden tener un carácter ilocucionario, es decir: cuando dicen algo hacen lo que dicen; y pueden, eventualmente, tener un efecto perlocucionario, pueden, con el tiempo, generar lo que dicen. Pero estos efectos no son lo mismo que el acto de habla. El efecto es una posibilidad latente, mas no algo inherente al acto de habla. ${ }^{22}$

31 Es precisamente desde aquí que podemos explicar parte del temor que la exhibición de las fotografías humillantes generaba. El mismo quedó enunciado desde las distintas personas que se manifestaron en el acto de apertura de la muestra en el Instituto de Formación Docente Continua de El Bolsón.

Cuando vimos las imágenes algunas nos resultaban sumamente fuertes, angustiantes, por momentos cuando las empecé a ver sentí una angustia física, algo en el cuerpo. Y ese malestar físico me hizo dar cuenta, fui reflexionando sobre qué podían sentir las comunidades si se acercaban a ver la muestra, en qué podían sentir otras personas, que no pertenecieran a ninguna comunidad que vinieran a ver la muestra. Y me pareció de mucha responsabilidad (Claudio Barrientos, bibliotecario IFDC, acto de inauguración, 21 de marzo de 2018).

(...) en esta muestra hay fotos que yo ya conocía y hay fotos que no, y sinceramente me generó esa duda interna acerca de qué mostrar, qué no y por qué, y desde qué fundamentos. Así que en estos días fuimos construyendo esta tensión entre todos, porque a todos nos pasaron cosas. Y encontrarse aquí hoy con las fotos que decidimos que se pueden mostrar y otras que no, por la humillación que representan para nuestros ancestros (...) Así que agradecida por haber podido construir en conjunto esto y haber tomado la decisión que tomamos en forma conjunta. (...) y poder acordar lo que nosotros consideramos, qué se puede mostrar, qué se puede ver, pero qué también se puede decir en palabras, y eso que no se puede mostrar por el grado de humillación que representa para nosotros (Elisa Ose, Comunidad Las Huaytecas, acto de inauguración, 21 de marzo de 2018).

Según uno de los bibliotecarios del instituto, exponer esas fotografías implicaba un doble riesgo. Por un lado, aquel de que alguien entrara a la institución, viera esas fotografías exhibidas y reconociera allí a un ancestro o ancestros que forman parte de su propia historia. Por el otro, el riesgo residía en que "se normalizara la mirada"; esto es, el temor de que se terminara naturalizando que es válido exhibir de esa manera a los indígenas; 
que, de hecho, esa es la forma de representarlos. Es decir, el temor provenía de asumir en primer lugar- que las personas que vieran la muestra respondieran a la interpelación que las fotos proponían: quienes fueran indígenas iban a sucumbir en una interpelación que coadyuvaba a una constitución subalternizada de su subjetividad. Quienes no lo fueran-por el contrario- iban a naturalizar que esa es la manera en la cual se representa a las personas indígenas. Siguiendo los planteos de Bruno Latour (2008) respecto de la religión, su forma de predicar la verdad y de llegar a los fieles, en este caso podemos pensar que las fotografías eran evaluadas como amenazantes no solo por el contenido de las mismas sino por el modo de enunciar y la transformación que pudiera operar en los receptores. El autor, haciendo una comparación con las conversaciones entre amantes, refiere que ciertas fórmulas se juzgan, y son exitosas, en sus capacidades performativas, en producir lo que enuncian. Si algo es fundamental en el éxito de la enunciación de los amantes y en el religioso es la capacidad de "traer al oyente y también al hablante a la misma proximidad y al mismo sentido renovado de presencia" (Latour, 2008, p. 23). En este planteo la fuerza de las imágenes reside en "continuar el proceso iniciado por una imagen en una prolongación del flujo de imágenes" (Latour, 2008, p. 37). Es entonces desde este planteo que podía entenderse el deseo de la comunidad y de parte de la institución: aquel de cortar el flujo que permite que un cierto significado sea transmitido como verdad (Latour, 2008).

Esto venía a sumarse a algo que muchos de los presentes en la inauguración -aun cuando habían tenido posiciones encontradas respecto de qué hacer con la muestra- reconocían: estas fotos habían sido publicadas y reproducidas, sin ningún tipo de perspectiva crítica, en libros de texto de nivel primario y secundario durante décadas y muchos son libros aún vigentes en las escuelas. Había un reconocimiento de que esas fotos habían contribuido a cimentar una determinada imagen del indígena: pasado, aislado y sometido. El temor, para el bibliotecario que recibió la muestra, estaba vinculado a que las fotografías colgadas en el pasillo, sin ningún tipo de pedagogía de su lectura, sin tiempo con cada visitante o persona que circulara por el pasillo para operar la impugnación que las fotos requerían, confluyeran en el mismo repertorio narrativo naturalizador por el cual las fotos habían circulado por décadas en los libros de texto; tan naturalizadas y reiteradas resultaban esas imágenes en el imaginario de las personas escolarizadas. El temor, entonces, era que, lejos de "congelar el cuadro" (Latour, 2008) -para poder analizarlas crítica y distanciadamente- las fotografías colgadas en la pared continuaran el flujo de significado de su origen.

Pero a su vez, las fotografías resultaban hirientes por otro motivo más que quedó plasmado en las alocuciones de la apertura y que también hacía al contexto inmediato en que las mismas eran exhibidas. Hacía poco más de dos años la Comunidad Las Huaytecas había solicitado al Museo de Ciencias Naturales de La Plata, y había obtenido, la restitución del cuerpo de Margarita Foyel, una de las "prisioneras de la ciencia" exhibida en esas fotografías.

Nosotros vivimos muy de cerca la restitución de los restos de Margarita Foyel, en un principio cuando iniciamos los trámites necesarios parecía una cosa lejana, pero fue muy doloroso para nosotros ver en qué condiciones estaban esos cuerpos y ver qué hicieron con nuestros antepasados, con nuestra gente, con nuestro pueblo. Entonces hay fotos que no se podían, o no se puede seguir mostrando la humillación que ha sufrido nuestro pueblo, porque algunos la entienden y otros no, pero nosotros sí la sentimos. La sentimos muy adentro y con mucho dolor porque esto no hace tantos años que ha pasado. Así que estamos en un proceso de restitución de los 
restos de los que fueron prisioneros en el Museo de La Plata y con una historia muy cruel de cómo han sido exhibidos y como los han maltratado. Una historia muy larga que contar, pero para que entiendan por qué razón nosotros manifestamos que algunas fotos no estuvieran presentes en esta muestra, es solo una cuestión de respeto a nuestros mayores y una cuestión de sentimiento a nuestras propias comunidades y respeto a nuestro pueblo (Mirta Ñancunao, Werken de Las Huaytecas, acto de apertura, 21 de marzo de 2018). nos volvía vulnerables frente a los performativos perlocucionarios, así también puntualiza la autora (Butler, 2014 [1997]) que la amenaza comprendida en el acto de habla es solo una posibilidad y el intervalo transcurrido desde la misma puede hacer que no se concrete; es decir, la respuesta a la amenaza es siempre imprevista y puede echar por tierra su poder performativo (Butler, 2014 [1997], p. 31). En este sentido, "las palabras son capaces de desligarse del poder de herir, y de recontextualizarse de formas más afirmativas" (Butler, 2014 [1997], p. 36). En todo caso, lo que se estaba expresando en esa sala, es que mediante la restitución de los restos de Margarita Foyel la comunidad había podido "hacer otra cosa" con ese cuerpo violentado por la prisión, romper el conjuro de la disposición humillante ${ }^{23}$ de su contexto original, el del cautiverio que mostraban las fotos. Por eso es que resultaba tan desconcertante volver a recibir dichas imágenes de cautiverio que, de alguna forma, volvía a interpelarlos en una clave que habían logrado superar hacía más de dos años.

Así lo ponía en palabras otro asistente:

La comunidad, a partir de ese movimiento de restitución, reclama los restos de Margarita Foyel para que sean devueltos a su comunidad pero no en una forma de exposición. Esto sucedió hace uno o dos años. En ese contexto, que vuelvan a aparecer fotos de Margarita Foyel en este formato de exhibición es fuerte. No me extraña que la impugnación haya venido de esa misma experiencia. En Buenos Aires puede que se muestren sin mayores conflictos, pero acá, en el contexto de las luchas de las comunidades indígenas y particularmente en el contexto de ellos, es lógico que tengan algo que decir al respecto [El resaltado me pertenece] (Carlos Masotta, antropólogo, acto de apertura, 21 de marzo de 2018).

Y es que, siguiendo a Butler (2014 [1997]) la comunidad había logrado -vía el largo proceso que llevó al entierro de Margarita Foyel en 2015- separar esas imágenes de su contexto de producción original y reestructurar el contexto desde otro acto de enunciación: la ceremonia de entierro en su lugar de origen.

En este sentido, la comunidad ya había logrado realizar una contra-citación del lenguaje hiriente del Museo de Ciencias Naturales de La Plata, citarse contra los propósitos originales del mismo y producir una inversión de sus efectos (Butler, 2014 [1997]). Sorprendentemente, el instituto -donde ahora se exhibía la muestra- se había articulado con la comunidad en determinados hitos de dicho proceso ${ }^{24}$ contra-citacional y ahora volvía, sin quererlo, a reinstalar imágenes cuyo contexto había sido desestructurado por la comunidad.

Es cierto que esas fotografías no ingresaron al instituto de la mano de quienes las habían tomado en el momento en que esas personas estaban cautivas sino por un colectivo que buscaba reparar todo ese daño. Entonces ¿por qué no podía recuperarse que el marco en el que las fotos llegaban a El Bolsón también las impugnaba y no pretendía reproducir el lenguaje de odio original? ¿Qué estaba obturando -en todo caso- la posibilidad de leer en esa clave la muestra de GUIAS? 


\section{¿Quién impugna qué marcos?}

40 ilegal". El discurso de los organismos de derechos humanos ya estaba instalado en la clase media y se había logrado un consenso generalizado respecto de los horrores de la dictadura. Por el contrario, las fotos que formaban parte de la muestra de GUIAS habían sido tomadas en el marco de un proceso que había estado lejos de ser ilegal. Si bien reconocía el bibliotecario- desde la academia argentina se trabajaba para calificar este proceso en tanto un genocidio, ${ }^{25}$ aún no había disponible un discurso público tan claro y contundente respecto de la aberración y horrores de dicho proceso. Además, el instituto estaba situado en el territorio de donde eran originarios muchos de los fotografiados. Estas dos cuestiones - concluía el bibliotecario- hacían ver que había que ser cuidadosos con la distancia histórica y temporal de los hechos. Al no reconocerse plenamente la aberración y estar naturalizada para sectores de la sociedad como un periodo de la historia nacional a la cual no se debería interpelar, era difícil que esa historia pasara a formar parte de un pasado impugnable. "Es como haber montado la muestra de ARGRA en el 78", concluyó el bibliotecario en una entrevista posterior a la muestra. Entonces, esto nos daba una pista de que el marco impugnador podía "confundirse" con uno reproductor porque en nuestro contexto histórico y territorial aún no se había operado una separación taxativa de ese pasado en tanto situación a repudiar. Ese pasado era hoy: lo era con las persecuciones y entradas violentas a los territorios mapuche, lo era con la muerte de Rafael Nahuel, era hoy con el encarcelamiento del Lonko Facundo Jones Huala. Lo que mostraban esas fotografías - según dicho profesional- eran antecedentes de un genocidio que aún se profundizaba en silencio, sin ser reconocido como tal.

Esto es, había un esquema de inteligibilidad que posibilitaba normas de reconocibilidad ( Butler, 2010 [2009], p. 21) de un proceso horroroso que la sociedad democrática se había prometido no repetir - el terrorismo de Estado producto de la última dictadura cívico- 
militar-; pero dicho esquema tendía a desvanecerse en relación a la denominada "Conquista del Desierto". Para aquello no había aún normas de reconocibilidad disponibles o lo suficientemente sólidas que permitiesen operar el reconocimiento de los fotografiados en tanto víctimas del accionar del Estado. Esto es lo que hacía muy dificultoso - para algunos- pensar que ambas muestras podían tener un tratamiento similar.

Como veremos en el próximo apartado, en este mismo sentido podían leerse las intervenciones que tenían que ver con los tiempos en los cuales se ubicaban los hechos que las fotografías plasmaban. Mientras algunos buscaban mostrar la continuidad y anulaban el tiempo, otros arrinconaban esos hechos al pasado. En todo caso, ese pasado nos ofrecía su resplandor para entender el presente.

La muestra de GUIAS había tenido por objeto ser crítica del momento en que fueron tomadas las fotografías. Retomando a Butler, entender al marco como un "romper con" o "alejarse" (2010 [2009], p. 27) implica que "una realidad que se daba por descontada es puesta en tela de juicio, dejando al descubierto los planes instrumentalizadores de la autoridad que intentaba controlar dicho marco" (2010 [2009], p. 28). Y esta era, sin duda, la intención del Colectivo y fue aquella de los bibliotecarios del instituto al decidir traerla. Sin embargo, esta operación de poner en tela de juicio el contexto productor de las fotografías por parte de GUIAS se veía desvirtuada por dos razones: una que se vinculaba con la forma en que la muestra de GUIAS construía el lenguaje de enunciación de dicha ruptura; la otra que ponía en cuestión la pertinencia de la agencia encargada de desmontar el marco original y ofrecer otro impugnador.

Esto de "Prisionero de la Ciencia" es una metáfora porque primero fueron prisioneros militares, prisioneros de guerra y después son trasladados desde esa experiencia a los museos. No es la ciencia la que los toma prisioneros, sino que es la avanzada militar que los hace prisioneros (Carlos Masotta, acto inaugural, 21 de marzo de 2018).

Tal vez la intervención de este antropólogo pudo poner en palabras cuál era la parte del marco impugnador que no lograba romper acabadamente con el marco original y erigir uno nuevo. Tal como lo planteaba Masotta, "Prisioneros de la Ciencia" era un eufemismo. Se estaba intentando "maquillar" o desdibujar el contexto original: esos indígenas eran prisioneros de guerra, y el marco impugnador -la muestra de GUIAS- no lo llamaba por su nombre sino que sustituía un término por otro. Volviendo a Butler, ella explica que en inglés, el verbo to frame puede significar "enmarcado": un cuadro está enmarcado. Pero también un delincuente puede estar framed; es decir, falsamente enmarcado (inculpado). En esta segunda acepción, estar enmarcado, explica Butler (2010 [2009]), significa ser objeto de una artimaña, de una operación fraudulenta, con pruebas falsas, que inculpan al sujeto inocente.

Volviendo a su otra acepción, el marco puede funcionar enmarcando, esto es, ampliando la imagen, pero también como un "embellecimiento editorial de la imagen", como un "auto-comentario sobre la historia del marco propiamente dicho" (Butler, 2010 [2009], p. 23). Llamar a la muestra "Prisioneros de la Ciencia", ofrecía un marco impugnador respecto del primer marco en que las fotos fueron tomadas. Sin embargo, ese nuevo marco, que venía a ofrecerse -en esta instancia- al instituto y a la comunidad de El Bolsón y la Comarca, funcionaba en la segunda acepción del término: el marco funcionaba a manera de embellecimiento editorial de aquello; la ruptura $-y$ en especial la tematización de la avanzada militar a fines del siglo XIX- se mostraban desvirtuadas al 
poner la agencia de la prisión en la ciencia y no en la guerra ni en el ejército. Esto, entonces, generaba una cadena por la cual la agencia impugnadora perdía fuerza en este contexto.

51 Así lo enunciaba Elisa Ose durante la apertura de la muestra, refiriéndose al objetivo impugnador de GUIAS:

(...) no dejamos de ser sujetos que estamos siendo estudiados. No dejamos de ser una cosa, en vista de la gente que vive en este Estado argentino. Como que me genera esa inquietud. Por ahí uno el vejamen que ve o la injusticia que ve a partir de las fotos, aparte de ser prisioneros, todo eso que esta sociedad tal sabemos que está mal. Pero a través de la imagen también hay un daño espiritual muy fuerte que cometieron Moreno y todos los que sacaron las fotos y es el hecho de que la foto dentro de nuestra cultura no va porque los abuelos nos dicen, porque te quitan el espíritu. O sea que además de habernos quitado la libertad, nuestros territorios, habernos despojado de nuestra cultura, nuestra identidad, nuestro idioma, nuestra familia, también hay que agregar una denuncia más, que a nuestros ancestros a los que fotografiaron les sacaron su espíritu, así que digamos, el daño es muy tremendo y en esas fotos que no se muestran ahora, había abuelos y abuelas, niños y niñas que fueron fotografiados en una situación de abuso, sexual si se quiere, así que peor todavía. Entonces quién lo decide. El dueño de la muestra, el que rescató esto y que denuncia lo que hizo el Estado o lo decidimos las víctimas. El patrimonio cultural ¿que incluye? ¿Qué pasa con las familias de desaparecidos de la última dictadura militar? ¿Qué pasa con el archivo histórico que hay ahí, está a disposición de toda la sociedad argentina? ¿Debe estar? ¿Es patrimonio histórico o es algo familiar, de uno? Eso es lo que me puse a pensar en estos días. Cómo miramos y qué queremos mostrar. Agradezco la intención de la muestra pero más allá de eso, replantear estos conceptos que tiene que ver con cosmovisiones que son distintas. Es muy fina la línea, hasta qué punto invado o no invado. 0 me dejo ser invadida o no por esa otra cultura, si se quiere, mayoritaria ${ }^{26}$ [El resaltado me pertenece].

Las representantes de la comunidad Las Huaytecas estaban poniendo en cuestión quién debía arrogarse la autoridad para impugnar los marcos originales de producción de las fotografías y sumaba otro ingrediente, además del eufemismo antes señalado. Esto es, la muestra impugnaba, en todo caso y sin llamarlo por su nombre, el marco original de las fotografías. Sin embargo, dejaba incuestionado el instrumento y la acción de fotografiar indígenas. Los miembros de la comunidad mapuche presentes en el acto sostenían que la fotografía había significado un violentamiento más ${ }^{27}$ y otro despojo: el del alma. Sin embargo, dicha acción quedaba incólume en la impugnación ofrecida por GUIAS, razón por la cual ellos debían elegir qué hacer con las fotos. Parafraseando a los autores decoloniales ya citados podemos decir que la misma acción de fotografiar era denunciada por quedar oculta al enumerar -en el acto de apertura de la muestra- otros dispositivos de manipulación de subjetividades propios de la fundación de "la herida colonial" (Gómez y Mignolo, 2012; Mignolo, 2005).

Si, según el bibliotecario -y poniéndolo nosotros en palabras de Butler- no había normas de reconocibilidad respecto de los horrores de la avanzada militar sobre territorio indígena a fines del siglo XIX que permitieran identificar el horror aun en un proceso que en su momento no había sido ilegal -o que había marcado una suerte de bisagra en la fundación de una nueva relación entre legalidad-ilegalidad ${ }^{28}-$, la comunidad llamaba la atención respecto de que tampoco se estaba reconociendo -o al menos no quedaba debidamente enunciada en la impugnación del marco- que la fotografía misma había operado como instrumento de dominación produciendo un despojo más. El marco que ofrecía GUIAS no resultaba entonces lo suficientemente contundente porque en palabras 
de Butler ofrecía un "embellecimiento editorial de la imagen" y también del marco pretendidamente impugnador. En ese sentido respondía a la segunda acepción de marco: enmarcaba injustamente e impugnaba a medias, por eso la necesidad de la comunidad de decidir ellos, en tanto víctimas, cómo denunciar y qué mostrar (y qué no) en esa denuncia.

Finalmente, se hacía una pregunta que venía a interpelar uno de los contextos de la muestra: aquel del conflicto el año previo con la muestra de ARGRA. En un punto esta intervención venía a dar una respuesta más de por qué ambas muestras no podían ser tratadas de igual manera. ¿Qué tipo de fotografías de los desaparecidos se mostraban públicamente? ¿Qué cuidados se tomaban al respecto? ¿Se exhibían públicamente fotografías de personas detenidas-desaparecidas durante la última dictadura cívicomilitar, desnudas y violadas?

\section{Reflexiones finales: aprender a ver el marco que nos ciega}

Hemos intentado hasta aquí recolocar los contextos de análisis (Briones y Ramos, 2018) que nos permitieran, por un lado, explicar el malestar que la muestra generaba aun cuando la intención de la misma -reconocida por todos- era impugnar los hechos fotografiados. Por el otro, intentar comprender entonces por qué cuando para la muestra de ARGRA se convino que exhibirla ayudaba a crear conciencia respecto de las aberraciones de la última dictadura, la misma operación no funcionaba para la muestra de GUIAS.

Las viñetas citadas al inicio de este trabajo, aun cuando se encuentran alejadas en tiempo y en espacio, resultan iluminadoras de aquello que quisiéramos dejar señalado en este escrito: que pese a que desde el instituto se intentó trabajar terrorismo de Estado en referencia a los pueblos indígenas de Patagonia, no había marcos de reconocibilidad de aquel horror que permitieran hacer comparables los dos casos.

Una de las cuestiones señaladas e indicadas que revelan ambas viñetas refiere al cuidado; al cuidado de los muertos y al cuidado de reproducir la herida. La segunda viñeta, por su parte, refiere a una situación en la cual la lejanía temporal y acaso el exotismo construido respecto de un cuerpo indígena del pasado, no permite ver en qué punto mostrar la fotografía de una niña cautiva violentada sexualmente debería resultar igual de hiriente que presentar la fotografía de un desaparecido torturado y muerto. ¿Qué encuentro ético, en todo caso, se volvía (im)posible en uno y otro caso? ¿Qué reconocimiento de la vulnerabilidad de qué vidas?

¿En qué sentido pasado y presente se unían para hablar de terrorismo de Estado pero en qué punto se estaba luchando para que determinadas situaciones no fueran arrojadas a un pasado ya finalizado del cual solo podíamos contemplarlo para que "nunca más" el horror estatal cayera sobre los pueblos indígenas?

La disputa en cuanto a considerar los hechos exhibidos en las fotos como pasados o como presentes también quedó escenificada en la apertura.

Para uno de los miembros del equipo directivo

(...) las imágenes que vamos a ver y los invitamos a recorrer y compartir con el resto de la comunidad, nos interpelan desde el pasado, y sobre ellas vamos a poder volver una y otra vez para poder añadir nuevas miradas. Desarmando y discutiendo sobre 
todo el discurso que circuló en la época en que estas fotografías fueron tomadas. Las imágenes no obstante, permanecen allí, mirándonos desde ese pasado, exhibiendo el poder de un Estado que en esa época, del S. XIX, y por mucho tiempo, utilizó a las instituciones educativas, a los museos y a las publicaciones de esa época para reforzar la idea de un supuesto orden social, de un supuesto capital cultural en el cual la fotografía y la iconografía tenía una visión totalmente eurocentrista y silenciaba y ocultaba todas esas otras culturas que se oponían con este ideal que se quería construir. Para revertir este discurso, instalado por décadas en los ámbitos educativos, creemos hoy que es responsabilidad de todos nosotros, y en particular de las instituciones de formadores de formadores, como es este Instituto, para reabrir el debate nuevamente, explorar qué se muestra y por qué ciertas imágenes adquieren valor y capacidad de circulación en la actualidad para construir una sociedad un poco más justa, un poco más inclusiva y pluricultural (Gabriela Sixto, acto de apertura, 21 de marzo). retratado por las fotos no era solo cosa del pasado y se empeñaron en

(...) decirle a los estudiantes que esto es parte de este territorio que se llama Argentina, que todos compartimos y que tiene esta historia tan triste y que no es que fue el pasado y nada más. Ese pasado tiene presente y ese presente aún sufre todas las consecuencias de ese pasado y no todo se ha solucionado (...) No es que se solucionó, y el pasado es eso que está en la pared. No. Pasado y presente están mezclados actualmente y no es que hemos dejado de luchar y estamos tranquilos mirando la tele en nuestras casas y nos hemos olvidado de todo lo que pasó [El resaltado me pertenece] (Mirta Ñancunao, acto de apertura, 21 de marzo.)

Podemos decir que los marcos que en un principio se creyeron "seguros" impugnadores estaban revelándose estallados, saturados por su propio peso. Al traer una muestra sobre los vejámenes sufridos por los pueblos indígenas, ¿se estaba hablando del presente o del pasado? Al incluir esta muestra en el repertorio del terrorismo de Estado ¿era una excusa para seguir hablando de Santiago Maldonado o para poner de relieve el sometimiento y avance presente del Estado sobre los territorios indígenas? ¿Pasado o presente? ¿Se encontraban disponibles esquemas de inteligibilidad que permitieran poner en paridad los marcos de reconocibilidad de ambas atrocidades? ¿Qué encorsetamiento no podía aun revelarse?

Para cerrar me permito citar una reflexión que inspiró el título del apartado.

Aprender a ver el marco que nos ciega respecto a lo que vemos no es cosa baladí. Si existe un papel crítico para la cultura visual en tiempos de guerra no es otra que tematizar el marco coercitivo, el conductor de la norma deshumanizadora, el que limita lo que se puede percibir y hasta lo que se puede ser (Butler, 2010 [2009], p. 143).

Finalmente, con este artículo pretendí poner en evidencia las distintas posiciones que se pusieron en acto para llamar la atención sobre aquello que aún no resulta inteligible para nuestros propios marcos. Para poder comprender aquello que se nos vuelve una interpelación y alertar sobre las interpelaciones que no somos capaces ni siquiera -al menos por ahora-de hacer inteligibles.

Es mi deseo haber dado, con este ejercicio reflexivo, al menos un paso en esa dirección. 


\section{BIBLIOGRAFÍA}

Barriendos, J. (2011). La colonialidad del ver. Hacia un nuevo diálogo visual interepistémico. Nómadas, 35, 13-29.

Barros, M. y Morales, V. (2016). Derechos Humanos y post-kirchnerismo: resonancias de una década y esbozo de un nuevo panorama político. Revista de Estudios Sociales Contemporáneos, 14, 104-124.

Briones, C. y Ramos, A. (2018). “Todo lo que es sólido (casi) se desvanece en el aire, todo lo sagrado (casi) se vuelve profano": manifestaciones discursivas de una crisis de hegemonía cultural. Revista Heterotopías, [on line] Año 1, 1. Disponible en:

https://revistas.unc.edu.ar/index.php/heterotopias/issue/view/1596/showToc

Butler, J. (2009 [2005]). Dar cuenta de sí mismo. Violencia ética y responsabilidad. Buenos Aires: Amorrortu.

Butler, J. (2010 [2009]). Marcos de guerra. Las vidas lloradas. Buenos Aires: Paidós.

Butler, J. (2014 [1997]). Lenguaje, poder, identidad. Madrid: Síntesis.

Claro, G. (abril 4 de 2018). La Fotografía como arma de dominación. Revista Cítrica, [on line]. Disponible en: http://revistacitrica.com/la-fotografia-como-arma-de-dominacion-.html

Delrio, W. (2010). Prólogo. En Colectivo GUIAS, Antropología del Genocidio. Identificación y restitución: "colecciones" de restos humanos en el Museo de La Plata, (pp. 10-11). La Plata: De la Campana.

Gell, A. (2016). Arte y Agencia. Una teoría antropológica. Buenos Aires: SB.

Martínez Luna, S. (2012). La antropología, el arte y la vida de las cosas. Una aproximación desde Art and Agency de Alfred Gell. AIRB. Revista de Antropología Iberoamericana, 7 (2), 171-195.

Gómez, P. y Mignolo, W. (2012). Estéticas decoloniales. Bogotá: Universidad Distrital Francisco José de Caldas.

Latour, B. (2008 [2005]). 'No congelarás la imagen' o cómo no desentenderse del debate cienciareligión. Etnografías Contemporáneas, 3(3): 17-43.

Lenton, D. (2014). De centauros a protegidos. La construcción del sujeto de la política indigenista argentina desde los debates parlamentarios (1880-1970). Corpus [En línea], 4 (2), URL: http:// journals.openedition.org/corpusarchivos/1290; DOI: 10.4000/corpusarchivos.1290

Masotta, C. (2017). La cicatriz de Margarita Foyel. Clepsidra. Revista Interdisciplinaria de Estudios sobre Memoria, 4 (8), 66-85.

Mignolo, W. (2005). La idea de América Latina. La herida colonial y la opción descolonial. Barcelona: Gedisa.

Muzzopappa, E., Tozzini, M. A. y Sabatella, M. E. (2018). Más allá del conflicto. La represión en la postpolítica argentina. En M. Barros, M. E. Muzzopappa, M. A. Tozzini y M. M. Quintana, (Eds.), Ideología, Estado, Universidad. Pensamiento Crítico desde el Sur. Viedma: UNRN Editora (En prensa).

Naranjo, J. (Ed.) (2006). Fotografía, antropología y colonialismo (1845-2006). Barcelona: Editorial Gustavo Gili, SL. 
Ribero Rueda, L. (2013). Alteridad y Colonialismo. La construcción de imaginarios y estereotipos en el retrato colonial y sus repercusiones en la fotografía contemporánea. Tesis doctoral inédita. Programa de doctorado en Arte, Territorio y Cultura de los Media. Facultad de Bellas Artes. Universidad de Barcelona. Disponible en:

https://www.tesisenred.net/handle/10803/116543

Schlenker, A. (2012). Hacia una memoria decolonial: breves apuntes para indagar por el acontecimiento detrás del acontecimiento fotográfico. Calle 14: revista de investigación en el campo del arte, 6 (8), 128-142.

Searle, J. (1980). Actos de Habla. Madrid: Cátedra.

Tozzini, M. A. (2016). Articulaciones, tensiones y reinscripciones en torno al proceso de restitución de Margarita Foyel. En Actas de las VIII Jornadas de Investigación en Antropología Social "Santiago Wallace" (pp. 1813-1823). 27 al 29 de julio de 2016. Facultad de Filosofía y Letras, UBA. Disponible en:

http://jiassw.filo.uba.ar/sites/jiassw.filo.uba.ar/files/viiijiassw_actas_final_0.pdf

Tozzini, M. A. (2017). Contienda en torno a la exhibición de la muestra fotográfica Archivos Incompletos (ARGRA). ¿Continuidad del duelo público o temor a su proscripción? Revista Identidades, 13(7), 59-78. Disponible en:

https://iidentidadess.wordpress.com/numeros-anteriores/numero-13/

\section{NOTAS}

1. Nos referimos al espacio donde se emplazaba la Escuela Superior de Mecánica de la Armada (ESMA), ubicada en la Ciudad Autónoma de Buenos Aires, Argentina. En parte de sus instalaciones funcionó uno de los mayores centros clandestinos de detención durante la última dictadura cívico-militar argentina (1976-1983). Desde 2004 funciona como "Espacio para la Memoria y para la Promoción y Defensa de los Derechos Humanos" congregando allí a distintos organismos de derechos humanos.

2. Se trata de fotografías entregadas a la Comisión Interamericana de Derechos Humanos en 1979 y que dicho organismo entregara al Estado argentino en 2011.

3. Damiana fue una niña aché capturada luego de que colonos blancos mataran a su familia en Paraguay a fines del siglo XIX. La niña fue llevada en 1898 a la localidad de San Vicente, en la provincia de Buenos Aires y destinada al servicio doméstico de la familia de un reconocido psiquiatra que tenía vínculos con el Museo de Ciencias Naturales de La Plata. Allí el antropólogo alemán Robert Lehmann-Nitsche se dedicó a estudiarla y fotografiarla. Al morir, en un reformatorio de Buenos Aires previa estadía en el hospital de Melchor Romero, su cráneo fue enviado a Alemania para ser estudiado. Parte de su cuerpo fue encontrado en el Museo de Ciencias Naturales de la Plata en 2006 y en 2010 restituido a su lugar de origen en Paraguay. El cineasta Alejandro Fernández Mouján volcó parte de esta historia en su film "Damiana Kryygi" (2015).

4. En adelante me referiré a dicha institución como "el Instituto" o simplemente "IFDC".

5. En 2015 se exhibió la "Muestra Anual de Fotoperiodismo argentino. Política-cultura-vida cotidiana"; en 2016, “Juicio a las Juntas"; y en 2017, “Archivos Incompletos”. Para más detalles de las mismas ver: www.argra.org.ar

6. Según consta en su propia página web, el Colectivo GUIAS es una organización autoconvocada de la Facultad de Ciencias Naturales y Museo de la Universidad Nacional de La Plata. Desde el año 2006 atiende reclamos realizados por los Pueblos Originarios respecto de la no exhibición y 
restitución a sus comunidades de los restos humanos que forman parte de colecciones arqueológicas del museo. En pos de esos objetivos trabajan en la identificación de los restos para su posterior restitución. (http://colectivoguias.blogspot.com) (Consulta: agosto 2018).

7. http://colectivoguias.blogspot.com/2013/02/prisioneros-de-la-ciencia.html (Consulta: agosto 2018).

8. La presión y el repudio de los organismos de derechos humanos y de los artistas en general derivaron en la renuncia del funcionario en junio de 2016.

9. En Tozzini (2017) analizo, también desde la perspectiva de Judith Butler, el conflicto tramitado en torno a la exhibición de aquella muestra. Citar aquí este trabajo implica dar datos precisos de los actores e institución participantes en tal conflicto (desdibujados entonces en el escrito a los fines de mantener el anonimato en virtud del malestar que había generado). Sin embargo, y en función de que en todo el proceso de debates respecto de la muestra de GUIAS -en análisis en el presente escrito - se conversó públicamente respecto del conflicto con la anterior muestra de ARGRA, utilizándolo permanentemente como objeto de análisis y reflexión retrospectiva, entiendo que ya no existirían motivos para mantener oculta la identidad de la institución y de los actores implicados en aquella contienda.

10. Su Chillkaltufe -Elisa Ose- organizó y participó de distintas actividades en el Instituto, además de haber formado parte -entre 2013 y 2015 inclusive- del Equipo de Interculturalidad de la institución.

11. En el marco de la investigación realizada en la zona limítrofe entre el sudoeste de Río Negro y el noroeste del Chubut desde 2002 (Tesis de Licenciatura en Antropología en la Universidad de Buenos Aires) he indagado en la fricción que los temas indígenas generan en un espacio que construye su relato oficial desconociendo el poblamiento indígena de larga data. Vivo en la zona hace casi dos décadas, he trabajado en el IFDC y luego he formado parte de su Equipo de Interculturalidad en tanto investigadora externa- por lo que fui convocada a algunas reuniones previas a la muestra, para reflexionar sobre el conflicto y posteriormente invitada a su apertura. Si bien en esas reuniones el equipo directivo manifestó la necesidad de una devolución, para el armado de este artículo decidí no incorporar lo conversado en esas reuniones más "íntimas" y solamente recuperar los fragmentos significativos del acto de apertura así como de entrevistas realizadas a posteriori con el objetivo expreso -y así enunciado- de la escritura de este artículo que, espero, pueda ayudar a reflexionar distanciada pero ubicuamente sobre dicho proceso.

12. http://colectivoguias.blogspot.com/2013/02/prisioneros-de-la-ciencia.html

13. Resulta imposible en este espacio dar cuenta de la cantidad de autores que han trabajado la relación entre fotografía y mirada colonial. Para un panorama del tópico ver Barriendos (2011) y Naranjo (2006), entre otros. Sobre este tópico en relación con el pueblo mapuche, ver Ribero Rueda (2013).

14. En efecto, durante la apertura en El Bolsón, el bibliotecario leyó un fragmento de una publicación donde Walter Delrio (2010) ofrece una pintura de lo que generó en distintos sectores la exhibición de la muestra en Bariloche.

15. Cabe aclarar que, en 2018 y luego de su estadía en El Bolsón, la muestra fue recibida nuevamente por la Universidad Nacional de Río Negro en Bariloche. Sin embargo esta vez, y en virtud de la experiencia conflictiva de la exhibición en El Bolsón, del cambio en el contexto local y la alta conflictividad -tópicos a desarrollar más adelante-, sumado a que ya se la había exhibido en 2010, no se montó nuevamente en Bariloche.

16. La Comarca Andina del Paralelo $42^{\circ}$ se compone por las localidades chubutenses de Lago Puelo, El Hoyo, Epuyén, El Maitén y Cholila y por la rionegrina de El Bolsón. En adelante podré referirme a ella como "Comarca Andina" o simplemente como "la Comarca".

17. El joven fue asesinado la misma tarde en que en su ciudad natal - 25 de Mayo, en la provincia de Buenos Aires- velaban a Santiago Maldonado, encontrado sin vida a fines de octubre en el río Chubut, tras permanecer desaparecido durante 78 días. 
18. Pocos días después de la aparición sin vida de Santiago Maldonado, los autodenominados "vecinos unidos por un El Bolsón mejor" convocaron por las redes sociales a una concentración en una de las plazas emblemáticas de la ciudad para "hacerle frente al grupo del RAM", mientras instaban a "ponerle fin a esto, nos alejan el turismo y nos destrozan nuestras instituciones". La marcha era, como lo fue en anteriores ediciones, un claro apoyo a la Gendarmería Nacional y en contra del "descrédito" en el que, según estos sectores, había sido injustamente arrojada.

19. Resulta difícil enumerar y caracterizar a los distintos actores comprendidos en este sector; solo aclaro que entre estas personas los posicionamientos fueron muy disímiles, fundamentalmente en virtud de tradiciones y espacios de militancias previas (distintos gremios, partidos políticos, militantes sociales), de las luchas que independiente y previamente del caso Maldonado vehiculizaban o, incluso, de qué tópico de los tantos involucrados dentro de este conflicto ponían en foco a la hora de manifestarse públicamente: la desaparición de un joven a manos de las fuerzas represivas, la represión de una protesta mapuche, el motivo original de la protesta y corte de ruta en la Pu Lof en Resistencia, etc.

20. Fue, por ejemplo, el eje de las reflexiones de Mauro Millán, reconocido militante mapuche, en el cierre de las V Jornadas de Memoria, Verdad y Justicia que organizó la Fundación Universitaria Popular de Escobar en abril de 2018 en la ciudad de Esquel, provincia de Chubut. Dicho militante se refirió a las desapariciones de dos personas mapuche en 2013 -Genaro y Cristian Calfullancaen la localidad chubutense de Cholila y cómo las mismas no habían llegado a la prensa a nivel nacional, ni lo hacían tras cumplirse cinco años de la desaparición, no habiendo ningún indicio del paradero de estos trabajadores rurales.

21. Esta operación discursiva no es única, ni aislada, ni novedosa: en una entrevista a quien fuera Secretario de Cultura de la Provincia de Chubut en ocasión de la segunda restitución del cacique Inacayal, este ex funcionario refería que la restitución se había planificado para el 10 de diciembre de 2014, en aras de contribuir a los postulados de Memoria, Verdad y Justicia (Claudio Dalcó, entrevista 7 de marzo de 2016). Asimismo Carlos Masotta (2017) refiere un hecho similar de reconocimiento a Margarita Foyel en Bariloche, en el marco de la conmemoración del 24 de marzo.

22. Entendemos que este planteo puede ponerse en diálogo con la obra de Alfred Gell (2016) "Arte y Agencia. Una teoría antropológica” en tanto el autor llama la atención respecto de los modos en que un artefacto - en este caso la fotografía- puede afectar a las personas, movilizar respuestas emocionales, o provocar todo un abanico de acciones y de procesos sociales. Acordamos con el autor en la necesidad de "analizar la red de relaciones que rodean obras de arte particulares en marcos específicos de interacción” (Gell en Martínez Luna, 2012, p. 175). Si bien la agencia de las fotografías queda evidenciada en este caso, aquello que nos genera duda respecto de la pertinencia de utilizar los postulados del autor para nuestro análisis es si podemos considerar a esta serie de fotografías -tomadas por agentes estatales en contextos de sometimiento y privación de la libertad de los indígenas- en tanto artefacto "artístico". Así, es sugerente pensar con Gell (2016) si nos limitamos a considerar a cualquier artefacto cultural con poder de incidir en comportamientos y relaciones sociales. Sin embargo, la especificidad del artefacto artístico, hace que, al menos, debamos leer con cuidado el planteo del autor.

23. En una nota periodística del 29 de noviembre de 2015 - diez días después de la restitución de Margarita Foyel al territorio de la Comunidad de Las Huaytecas- en el programa radial "Es la luna la que habla", producido por mujeres mapuche de la Comarca y emitido por Radio Nacional y Radio Comunitaria Alas - ambas de El Bolsón-, Isabel Huala, referente mapuche de la zona, refería con angustia la manera en la cual habían recibido el cuerpo de Margarita Foyel: "se terminó la tortura, la cárcel para ella (...) impotencia muy grande haber visto el sufrimiento en los huesos (...) pusieron sus huesos con alambre por dentro para poder armar un esqueleto de una colección (...) ver sus manitos cruzados todos sus dedos por alambre". Otros entrevistados en el programa referían la forma en la cual la misma comunidad desarmó esa disposición durante la 
ceremonia que llevó a Margarita a su lugar de descanso final, quitándole las últimas amarras de cautiverio, "tener la tranquilidad de que ella ahora está libre" (Isabel Huala). Algo similar manifestaba en el mismo programa radial Rubén Curricoy respecto de cómo habían tenido que "desarmar" esa disposición corporal propia del cautiverio y "pasar a la bronca de nuevo cuando la ves ahí envuelta en bolsas, partes por partes, números grabados en huesos, cráneos, alambres cruzando sus dedos, sus manitos, sus piecitos (...) de seguir manoseando el cuerpo de una hermana [para poder enterrarla liberada de esa disposición], que no nos acostumbraron a eso".

24. Sobre el proceso de articulación que se gestó en torno de la restitución de Margarita Foyel, ver Tozzini (2016).

25. Remito a los lectores a las discusiones que sobre el tópico se publicaron en esta revista en su Volumen 1, No 2, Julio / Diciembre 2011. Disponible en: https://journals.openedition.org/ corpusarchivos $/ 887$

26. Este fue el eje de la nota periodística de Claro (2018), publicada días después de la inauguración de la muestra.

27. Esto se vio escenificado en el momento de la apertura de la muestra; varios de los presentes sacaban fotos con sus celulares $u$ otros dispositivos electrónicos, lo que generaba comentarios de reprobación por parte de las representantes de la comunidad, en el sentido que entendían que se los seguía cosificando, se seguía usando acríticamente la herramienta.

28. Agradezco a uno de los evaluadores por haberme llamado la atención sobre este punto. Para interiorizarse sobre los debates parlamentarios previos a la campaña militar referida, consultar la tesis de Diana Lenton (2014), editada por esta revista.

\section{RESÚMENES}

Este escrito - producto de mi trabajo de campo etnográfico en la zona- analiza las tensiones que se generaron en una institución educativa de la localidad de El Bolsón -Río Negro, Patagonia argentina- en torno de la exhibición de la muestra fotográfica "Prisioneros de la Ciencia" del Colectivo GUIAS (Facultad de Ciencias Naturales y Museo de la Universidad Nacional de La Plata). Traída en ocasión del Día de la Memoria, por la Verdad y la Justicia -que conmemora la última dictadura cívico-militar - a los fines de poder reflexionar sobre el terrorismo de Estado en relación con los pueblos indígenas, algunos actores evaluaron que no era pertinente mostrar aquellas fotografías donde la humillación de los prisioneros era extrema.

Analizo el conflicto generado entre diferentes opiniones y posturas que se esgrimieron en el acto de apertura de la muestra fotográfica, desde la perspectiva de la teoría de los marcos de Judith Butler, asumiendo al grupo de fotografías exhibidas en tanto "actos de habla".

Resulta fundamental analizar la relevancia y conflictividad que la conjunción terrorismo de Estado-pueblos indígenas adquiere en El Bolsón a la luz de la restitución de los restos de Margarita Foyel - prisionera en el Museo de La Plata- en 2015, la desaparición de Santiago Maldonado y el asesinato de Rafael Nahuel en 2017.

This work analyzes - from my ethnographic field work in the area- the tensions that were generated in an educational institution in El Bolsón -Río Negro, Argentine Patagonia- around the photographic exhibition "Prisoners of Science", from the Colectivo GUIAS (School of Natural Sciences and Museum, University of La Plata). It was brought on the occasion of the Day of Remembrance, for Truth and Justice, which in our country commemorates the last civil-military 
dictatorship, in order to reflect on state terrorism in relation to indigenous peoples. Some participants evaluated that it was not pertinent to show those photographs where the humiliation of the prisoners was extreme.

I analyze the conflict among different opinions and positions which were evinced at the opening of the photographic exhibition, from the standpoint of Judith Butler's framework theory, assuming the group of photographs exhibited as "speech acts".It is essential to analyze the significant and conflictive conjunction of State terrorism and Indigenous peoples in El Bolsón in the light of the restitution of the remains of Margarita Foyel -prisoner in the Museum of La Plata - in 2015 and the disappearance of Santiago Maldonado and the murder of Rafael Nahuel in 2017.

\section{ÍNDICE}

Palabras claves: Muestra fotográfica, actos de habla, Judith Butler, terrorismo de Estado, pueblo mapuche

Keywords: Photographic exhibition, speech acts, Judith Butler, State terrorism, Mapuche people

\section{AUTOR}

\section{TOZZINI MARÍA ALMA}

Instituto de Investigaciones en Diversidad y Procesos de Cambio, Consejo Nacional de Investigaciones Científicas y Técnicas, Universidad Nacional de Río Negro, Argentina Correo electrónico: atozzini@unrn.edu.ar 